\title{
Apontamentos acerca da subjetividade e dos processos de subjetivação no mundo contemporâneo e suas repercussões na clínica psicoterápica
}

\author{
Notes about the subjectivity and the subjective processes in the modern world and \\ their impact on clinical psychotherapeutic \\ Notas acerca de la subjetividad y los procesos subjetivos en el mundo contemporáneo \\ y su impacto en la práctica psicoterapéutica
}

\author{
André Luiz de Oliveira ${ }^{I}$ \\ Ellika Trindade \\ Centro Universitário das Faculdades Associadas - UNIFAE
}

\begin{abstract}
Resumo
Este artigo tem como objetivo problematizar a questão da subjetividade e dos processos de subjetivação na contemporaneidade e suas repercussões na clínica psicológica. Buscou-se realizar uma revisão crítica sobre como se caracteriza a subjetividade e como ela se constitui nos dias atuais. Utiliza-se o conceito de pós-modernidade para caracterizar nosso viver contemporâneo, tentando descrever a dinâmica desta pós-modernidade de modo a relacioná-la com os processos de subjetivação desenvolvidos hoje em dia. Aborda-se a questão de qual poderia ser a atuação da Psicologia neste contexto, sendo oferecidas indicações acerca do possível posicionamento de seu profissional, para gerir e auxiliar verdadeiramente seus pacientes diante da atual conjuntura. Por fim, considera-se que abordar a questão da subjetividade é algo complexo, no entanto, é possível considerar que o psicólogo clínico interessado e disposto a ajudar realmente seu paciente a entender os processos que o envolvem atualmente, deve antes de tudo saber compreender estes processos.

Palavras- chave: Subjetividade; Processos de subjetivação; Pós-modernidade; Psicologia.
\end{abstract}

\begin{abstract}
This article aims to discuss the issue of subjectivity and subjective processes in the contemporary world and their impact on clinical psychology. We attempted to perform a critical review on how to characterize the subjectivity, especially nowadays. We use the concept of postmodernity to characterize our contemporary living in order to describe the dynamics of this postmodernity, relating it to the subjective processes developed nowadays. It also conducts to the question of what could be the role of psychology in this context, and we discuss the possible positioning of its professional in managing and helping their patients on the current situation. Finally, it is considered that directs the issue of subjectivity is complex, however, it is possible to consider that the clinical psychologist interested and willing to really help your patients to understand the processes that currently are involved, first of all, how to learn for understanding these processes.

Key-words: Subjectivity; Processes of subjectivity; Postmodernity; Psychology.
\end{abstract}

\section{Resumen}

Este artículo tiene como objetivo discutir la cuestión de la subjetividad y los procesos subjetivos en el mundo contemporáneo y su impacto en la psicología clínica. Se intentó realizar una revisión crítica sobre la forma de caracterizar la subjetividad y cómo es hoy en día. Utilizamos el concepto de pos-modernidad para caracterizar nuestra vida contemporánea, tratando de describir la dinámica de esta pos-modernidad, para relacionarlo con los procesos subjetivos desarrollados hoy en día. También se aborda la cuestión de lo que podría ser el papel de la psicología en este contexto, y ofreció una idea de la posible colocación de un profesional para manejar y realmente ayudar a sus pacientes sobre la situación actual. Por último, se considera que abordar la cuestión de la subjetividad es compleja, sin embargo, es posible considerar que el psicólogo clínico interesado y dispuesto a ayudar realmente a sus pacientes a entender los procesos que actualmente implican, debe en primer lugar aprender a entender estos procesos.

Palabras-clave: Subjetividad; Procesos de subjetivación; Pos-modernidad, Psicología.

Através da história, a questão do pensamento humano sobre si mesmo e seu modo de ser foi uma presença marcante na formulação das ciências humanas (Ales Bello, 2004). Levando em consideração tal questão, qualquer ser humano em sua vida cotidiana pode parar para refletir sobre si

Endereço 1: Rua Paulo Modesto, 341, Vale do Sol, CEP: 37200000, Lavras, MG, Brasil. mesmo, considerar sua forma de pensar, de agir, de comportar, de se vestir e de falar. E a partir daí, pode surgir à pergunta, o que é este seu modo de ser, e o que significa esta sua forma de existência?

Essa forma de existência do ser humano é o que na Psicologia, hoje, denomina-se de subjetividade. Mas, para entender como se chegou a esta problematização acerca do tema da subjetividade, bem como suas possíveis implicações para a clínica psicológica, 
é necessário tomar conhecimento de como esta especulação entrou no foco de conhecimento da Psicologia, e o que significa subjetividade.

Segundo Ferreira (2000), no inicio da consolidação da chamada ciência Psicológica na segunda metade do século XIX, o tema da subjetividade ainda não estava presente, a Psicologia em seu engatinhar como ciência tratava apenas de questões relativas à percepção, fisiologia do sistema nervoso e comportamento.

Somente em seu desenvolvimento posterior, este tema passa a fazer parte do campo de conhecimento desta ciência. Isto nos coloca a questão do quanto é nova a discussão acerca do tema subjetividade.

Primeiramente, o termo subjetividade de acordo com Prado Filho e Martins (2007) surge na modernidade com Kant (1724-1804), que buscava através de suas diversas elaborações teóricas instituir métodos para desvendar a interioridade humana. Só após o seu surgimento no século XIX, é que mais tardiamente, este conceito passou também a ser usado e compreendido na Psicologia. Sendo assim, segundo esses autores, foi só a partir da segunda metade do século passado que a compreensão acerca deste tema descentralizou seu sentido de pura interioridade, sentido o qual delineou seu surgimento, para ganhar contornos mais abrangentes considerando também as circunstâncias sociais, políticas e históricas.

Isto não significa que antes do surgimento da Psicologia o pensamento acerca da subjetividade não existia, muito pelo contrário, pois desde a Grécia antiga os filósofos já se questionavam sobre suas existências, suas almas e suas vidas. Coube primeiramente a filosofia o papel de investigação e elucidação dos mistérios do mundo e dentro desses mistérios o próprio homem.

Ferreira (2000) afirma que passando por Demócrito (460-370 a.C), Platão (427-347 a.C) e Aristóteles (384-322 a.C) na Grécia antiga até Kant (1724-1804), Hegel (1770-1831), Descartes (1596-1650) e tantos outros mais contemporâneos, todos esses filósofos investigaram e procuraram uma resposta sobre como se forma e funciona este complexo elemento da existência humana. Mas, nos dias atuais, no que tange ao conhecimento científico a Psicologia se torna um campo privilegiado para se buscar olhar mais acuradamente e de maneira mais atenta para este tema, já que ela tomou este âmbito como seu objeto de estudo.

Mas a partir do que foi exposto até agora sabemos claramente o que significa subjetividade? Já se esgotaram os esclarecimentos sobre o assunto?

Acreditando que não, discorramos um pouco mais sobre a subjetividade e o processo de subjetivação no mundo contemporâneo para podermos posteriormente apontar quais são suas repercussões na clínica psicoterápica. Ainda de acordo com Ferreira (2000), subjetividade é tudo aquilo que circunda o sujeito e o define, ou seja, a subjetividade é aquilo que pertence e singulariza cada sujeito, passando por sua história pessoal e coletiva, além da multiplicidade de estímulos a que ele está sendo exposto.

Rey (2003) aborda ainda na perspectiva da subjetividade, o conceito de sentido subjetivo como fator determinante da constituição desta. Para este autor, sentido subjetivo remete a acontecimentos históricos presentes na vida de cada sujeito que tenham sido tão marcantes emocionalmente para ele, que o sujeito atribui sentido a estes acontecimentos, e assim, estes passam a fazer parte de sua subjetividade tendo um papel importante nos processos de subjetivação futuros.

O processo de subjetivação é todo o jogo de relações que promovem esta subjetividade. Segundo Lemos (2007), a subjetivação é o resultado de uma prática concreta, que sai de todas as atividades do homem, seja nos jogos de poder em que ele está envolvido, seja através de suas práticas discursivas. Pensando desta maneira, pode-se dizer que o processo de subjetivação se dá a todo o momento, pois o homem o tempo todo está envolvido em relações de poder e se expressa e é influenciado através do discurso. Mas não é só através dessas relações de poder que se dá a subjetivação. Este processo é possível através de todas as práticas em que este homem está inserido, desde aquelas em que ele mesmo é ator principal, até aquelas em que ele é um mero espectador que sofre apenas influências do meio externo, passando por sua história pessoal e coletiva, além do meio cultural em que este vive.

Com isto chega-se a uma concordância com Prado Filho e Martins (2007), que consideram a subjetividade como movimento, sem um núcleo específico vindo de uma pretensa natureza humana. E se torna fundamentalmente importante a diferenciação entre personalidade e subjetividade neste bojo, pois a subjetividade se forma e se reforma dentro do cotidiano, o que implica movimento e elasticidade, através dos diversos elementos que atravessam o sujeito em seu dia a dia. Já a personalidade embora também possua uma margem de movimento se configura de maneira mais estática, sendo inclusive formada e moldada por esta subjetividade e os processos de subjetivação.

Assim, é importante não se confundir subjetividade com personalidade. Tal como foi abordado, a subjetividade em consonância com as formulações de Gonçalves (2011) é esse algo complexo que se faz e se refaz no dia a dia e que tem sido o alvo de descrição de nosso estudo até agora. Já a personalidade advém do que podemos chamar de síntese subjetiva que se configura como todo esse jogo dialético que ocorre entre sujeito e mundo e que se repete, criando um modo de ser mais cristalizado e passível de observação através do comportamento.

Essa síntese acontece quando através das experiências pessoais a que somos expostos desde 
nossa tenra idade formamos modos semelhantes de nos portarmos frente a esses acontecimentos. A repetição se dá dessa forma, com o nosso subjetivarse, vamos criando formas especificamente nossas de exteriorizarmos parte de nossa subjetividade, formas estas que nos parecem adequadas para responder às exigências externas que nos são oferecidas, mas que além de serem formas especificamente nossas, são também moldadas por fatores externos, como regras e convenções sociais, influência familiar e tantos outros fatores que nos fazem criar padrões de modos de ser, e responder a determinados eventos de maneira semelhante. Esses modos de ser podem ser observados através do comportamento, e, portanto, a psicologia trata esse modo específico de ser como personalidade. A personalidade se caracteriza então como um modo de ser que responde de maneiras semelhantes aos eventos do mundo, é um aspecto humano que se mostra mais regular, mais estável e de certa forma estático, sendo possível através da psicologia se aplicar testes com o intuito de predizer esta personalidade. Embora este termo chamado personalidade seja muito controverso na psicologia, pois recebe várias definições, segundo Piéron em sua definição da personalidade esta, pode ser representada como:

O que a personalidade representa, essencialmente, é a noção de unidade integrativa de um ser humano, pelo que, inclui todo o conjunto de suas características (atributos) diferenciais permanentes (constituição, temperamento, inteligência, caráter) e suas modalidades específicas de comportamento (Piéron, 1978, p.329).

Já a subjetividade na perspectiva que adotamos nessa reflexão, diferentemente, é algo fugaz, instável, e em constante mutação, não sendo passível de previsibilidade e de experimentação (Sartre, 2009).

Levando em conta as reflexões que fizemos, se quisermos realmente compreender como se dá tanto o processo de subjetivação, quanto a formação da subjetividade, devemos levar em consideração a complexidade de elementos que influem nesse processo. Segundo Lemos (2007) dentre eles, dois se mostram muito importantes: a história e a cultura. A cultura como sendo as formas e os modos de se agir, e de se pensar em determinada região, seja ela nacional, estadual, municipal, ou em determinado grupo específico; a história como sendo os fatos e os acontecimentos que marcaram e construíram determinados pensares, agires e saberes de determinado povo, grupo, ou região.

Lemos (2007) considera que se deva pensar a cultura não como algo estático e cristalizado, mas como algo dinâmico que está em constante transformação e que consequentemente, transforma os indivíduos que dela são oriundos. O que sem dúvida nos mostra que há coerência no pensar a questão da subjetividade, pois, se a cultura que é algo de fundamental importância na constituição desta, não é algo imóvel, fica difícil pensarmos a subjetividade dessa forma.

Quanto à história, ela refere-se não só ao nível da sociedade em que este indivíduo está envolvido, mas também àquela história pessoal que constitui este sujeito e molda sua visão de mundo. Para Rey (2003), pensar dialeticamente esta relação entre história individual, história social, sentidos subjetivos e cultura nos propiciará termos uma visão mais ampla de como dialoga a subjetividade com seus processos de subjetivação e, consequentemente, a formação desta subjetividade.

Pois bem, assim é que pensamos a subjetividade nesta discussão, como um elemento aberto em constante produção, e em constante diálogo com o cotidiano e com as forças que a atravessam. Além dos dispositivos envolvidos que promovem este diálogo e consolidam formas de pensar e agir, promovendo ou não consolidações de saberes e conscientizações acerca dos modos de vida a que somos estimulados a aderir nos dias de hoje. Nesta linha de raciocínio a subjetividade é pensada como algo que se constitui através de várias maneiras, e a partir de muitos acontecimentos presentes na vida das pessoas, eventos estes que se conjugam e dialogam para fornecer sua base.

Dessa forma Guattari (1992) afirma que a subjetividade é constituída através de uma heterogênese, ou seja, não há um fator preponderante que implique em sua constituição, mas sim, uma variabilidade de fatores, elementos e acontecimentos que cada um a sua maneira influi e contribui para que a subjetividade se forme e se estabeleça de sua maneira peculiar e pessoal. Essa pessoalidade que adquire a subjetividade, esse toque singular que cada ser humano carrega em seu modo de ser, advém não especificamente dos acontecimentos externos a que ele está exposto, pois duas ou mais pessoas podem compartilhar das mesmas vivências e influências externas como, por exemplo, partilharem da mesma cultura, serem criadas subordinadas às mesmas regras e tantas outras formas de padronizações de viveres que existem e que levariam a uma igualdade de subjetividades, e mesmo assim, serem diferentes em seu modo de ser. O que vai definir essa subjetividade singular é o processo de subjetivação envolvido, é a forma em que esse sujeito vai apreender esses acontecimentos e como ele vai significar e atribuir sentido aos mesmos. Este processo sim é pessoal e solitário e é através dele que a diferença irá se estabelecer.

Nestes termos é que Maciel Junior e Melo (2006) afirmam que é através de uma contemplação passiva que esta subjetividade se encontra com o mundo e se estabelece, ou seja, essa contemplação significa uma disposição natural para um entrelaçamento do sujeito com os acontecimentos do mundo, e desse entrelaçar nasce o subjetivo. Assim, os autores utilizam o 
conceito de Gilles Deleuze (1988) de contemplação passiva, para evidenciar a pessoalidade desse processo de subjetivação, que significa um encontro não só psicológico deste sujeito com o mundo, mas um encontro existencial, que assim sendo, só pode se realizar sozinho.

Dentre essa heterogeneidade de elementos que se conjugam para constituir a subjetividade um elemento que se pode considerar como um dos principais é a linguagem. Segundo Tedesco (2003) através da linguagem a subjetividade se forma e se reforma dentro da experiência de vida se configurando de uma forma coletiva e socializada de expressão e criação.

A linguagem se torna um meio privilegiado para que a subjetividade não só seja construída, como também se expresse e se reconstrua, pois a linguagem como principal elo do sujeito com o mundo possibilita a este, ao entrar em contato com ela, construir e reconstruir valores, originar e estimular reflexões e pensamentos criar e se expressar através da arte e de todos os meios de produzir linguagem que colocam essa subjetividade em jogo e em movimento.

Partindo desta perspectiva que adotamos para discutir a subjetividade passamos agora a refletir acerca do nosso mundo contemporâneo, mais especificamente sobre nosso contexto cultural, nos restringindo é claro, à dimensão do Brasil. O Brasil como nosso ambiente cultural mais próximo se torna campo de discussão e reflexão sobre o modo como nossa cultura vem promovendo processos de subjetivação e constituição de subjetividades. Para discutirmos e refletirmos acerca desse processo usaremos vários autores que não são brasileiros, mas que de alguma forma nos ajudam a pensar a contemporaneidade, já que o Brasil como pertencente a era da globalização, em nossa visão, compartilha de muitos dos usos culturais que atualmente se manifestam no Ocidente.

A partir das considerações relativas à contemporaneidade brasileira discutiremos em seguida sobre como a Psicologia pode lidar com estas subjetividades e processos de subjetivação contemporânea na clínica.

Podemos afirmar que, segundo observação de Evangelista (2008) vivemos hoje na era da pósmodernidade. Embora pós-modernidade não seja diretamente o foco deste texto, este termo, que também é usado por tantos outros autores será adotado aqui como meio de destacar a era em que vivemos. Dessa forma, a pós-modernidade em Barth (2007) é a era do consumo, da polissemia de informações, da diversão sem limites, da busca por prazer a qualquer custo. Enfim, uma era aberta e cheia de possibilidades, em que as diferenças que se configuravam como tabus de outrora, foram absorvidas pelo mercado sendo proibidas e permitidas de acordo com a conjuntura, e o incentivo a formação de consciência crítica é deixado de lado pelos formadores de opinião, ficando então restrito às universidades meio sem força para influenciar a sociedade.

A diferença quando é permitida, se exprime no uso dos corpos, nas manifestações sexuais, no uso dos prazeres e nas manifestações culturais. Embora ainda não estejamos livres do preconceito e de suas várias formas de discriminação, esses tipos de manifestação são tolerados desde que movimentem a economia e não afrontem diretamente o pilar que sustenta nossa cultura ocidental, ou seja, o capitalismo e seu combustível, o consumo.

Essa permissão por conveniência de que falamos está presente em vários contextos sociais de nossa vida cotidiana nos dias de hoje como, por exemplo, na esfera sexual quando vemos a permissão para que os homossexuais façam passeatas exaltando o orgulho de ser homossexual ou quando vemos este tema antes interdito entrar na agenda de discussão de governos, religiões ou ser explorado pela mídia tanto como elemento polêmico como entretenimento para as massas. O fato de que as mulheres cada vez mais se estabelecem em pé de igualdade com os homens minando cada vez mais as estruturas de uma sociedade patriarcal que há séculos vigorava no ocidente também se mostra paradigmático para que compreendamos a mudança cultural que ocorre em nossos dias (Lipovetsky, 2000).

E encontramos fatos como este não só na esfera sexual, mas, também nas áreas sociais como os movimentos sindicais, os pecuários, na área religiosa, ou até mesmo na área da saúde mental com a discussão sobre os loucos e seus direitos. E tantas outras esferas da nossa vida contemporânea. Tudo isso condicionado a movimentação da economia, no respeito ao cânone do consumo e da ampliação de mercado. O que por um lado pode ser considerado um ganho para a democracia, por outro revela também um processo de enfraquecimento das velhas estruturas sociais. $\mathrm{O}$ que leva de certo modo a uma perda de referências, já que o questionamento das instituições de outrora indica também uma fraqueza por parte destas no que tange a influenciar a sociedade atual. Esta questão se revela como um estado de transição em que uma visão de mundo morre enquanto outra nasce e neste ínterim as subjetividades ficam marcadas por ambas as visões transitando freneticamente entre elas sem se ater a nenhuma delas.

Disso podemos dizer que nos encontramos em situação semelhante a que descreveu Rollo May quando versava sobre o homem moderno:

$O$ fato central é que vivemos num daqueles momentos da história em que um tipo de vida se encontra em agonia e outro começa a surgir, isto é, os valores e objetivos da sociedade ocidental encontramse em estado de transição (May,1994, p.39).

Portanto, a situação se repete doravante nos tempos atuais as questões sociais se encontrem em um processo ainda mais volúvel que na era moderna, 
além do fato de hoje nos defrontarmos com uma multiplicidade de provocações tanto sociais, como subjetivas que antes não existiam. A esfera sexual que citamos serve para ilustrar o que atualmente ocorre em nossa contemporaneidade. Já que este aspecto, o sexual, até o advento da pós-modernidade a que nos referimos, se configurava como um dos maiores tabus que vigorava em nossa sociedade. Referimo-nos a um processo de transição entre duas visões de mundo, devido ao fato de que por mais que estes temas hoje transpareçam com mais naturalidade, ainda não há uma liberação total, esses temas ainda provocam mal-estar quando são discutidos, mas diferentemente de tempos atrás hoje eles são discutidos. O que evidencia como dissemos esta perda de referências, pois estamos sob influência tanto do modo de ser constituído ao longo da modernidade, já que os laços não foram totalmente rompidos por isso o mal-estar, e ainda existem tabus e ideologias tradicionais, como também da pós-modernidade com sua dinamicidade e busca de novos paradigmas.

Estes elementos contraditórios muitas vezes nos tornam confusos e dificultam a comunicação e o entendimento entre as novas e as velhas gerações que nesse mosaico cultural buscam se relacionar e se compreender.

Em relação à posição da formulação da consciência crítica na atualidade, uma das grandes disciplinas que nos auxiliaram e auxiliam na formação desta, além da Psicologia, é a Filosofia. Mas, em se tratando do discurso filosófico o que nos parece, em se tratando de Brasil, é que a filosofia enquanto epistême que estimula o pensar fica relegada aos muros das Universidades. Assim mesmo, nem em todas as Universidades se ensina a filosofia como compreendida por Heidegger (2008), ou seja, aquela que estimula o questionar, o refletir, o pensar e o agir, aquela que promove e facilita uma transformação social. No Brasil, apesar de não negarmos sua presença em muitas instituições de ensino superior, essa concepção dificilmente é ensinada nas escolas ficando basicamente restrita a alguns polos acadêmicos que acabam se sobressaindo como pontos de conhecimento em uma conjuntura de alienação. A filosofia ensinada nas escolas públicas no Brasil, em nossa percepção, se mostra mais uma filosofia histórica, ou seja, que descreve autores cujas ideias não são relacionadas ao contexto atual, o que acaba por não estimular a continuidade do pensamento, não sendo assim uma disciplina que ajuda a pensar a sociedade e suas descontinuidades visando questioná-la e transformá-la. Corroborando com esta avaliação sobre a situação da filosofia no Brasil, Bittencourt afirma:

Podemos comprovar, de acordo com a situação prática de nossa educação nacional, que poucas instituições de ensino no Brasil concedem ao estudo da disciplina de Filosofia o destaque e a autonomia adequados para a criação e desenvolvimento de uma estrutura que favoreça o exercício do pensamento entre os jovens. Essa situação de declínio cultural motiva, por conseguinte, uma estagnação da afirmação da capacidade criativa do ato de pensar, além da exclusão considerável de uma grande quantidade de jovens em estado efervescente de formação existencial, intelectual e cultural, na plena possibilidade de se posicionarem de modo crítico perante as polêmicas questões cotidianas do mundo circundante e da vida (Bittencourt, 2008, p.58).

Este fato acaba servindo a uma manutenção do sistema dominante sem uma busca por questionálo na tentativa de aprimorá-lo, mantendo as massas alienadas, e transformando os poucos que têm acesso a outro modo de pensar e a outra forma de conhecimento, e que por isso mesmo questionam o status quo, em pessoas consideradas "intelectuais" ou "excêntricas" dependendo da condição social em que vivem. Os restringindo a categorias que não se popularizam e assim, os mantendo em um grupo seleto aprisionando o pensar. Essa lógica da pós-modernidade de priorizar a instrumentação através do desenvolvimento tecnológico à revelia do pensamento, vai restringindo aos poucos as ciências humanas relegando-as a segundo plano, e condenando-as a categoria de "ciências menores" em uma esfera de competitividade e produção constante. Já que o pensamento acerca da dinâmica social fica sem lugar e rouba o tempo que poderia ser despendido na cadeia produtiva ou na atividade consumista, o que se configura como um entrave ainda maior para a transformação social, pois em nossa concepção, as ciências humanas se configuram como indispensáveis para um processo de mudança social.

Esse modus operandi da contemporaneidade vai criando segundo Crochik (2010), sujeitos sem subjetividade, ou indivíduos que priorizam a forma em detrimento do conteúdo. Então, a estimulação à busca pela felicidade constante, ao prazer sem limites e ao individualismo extremo, induz o sujeito a ser vazio e superficial. A não refletir sobre suas questões e de sua sociedade, não conseguindo construir um jeito de ser próprio e não tendo por sustentação convicções próprias, ficando assim sempre sujeito a pensar de acordo com a moda e com o que vem sendo dito pela mídia tornando-o então deficiente de consciência crítica. O que vai ao encontro com o que Baumam (2001) diz sobre a sociedade líquida em que vivemos, pois tudo é fugaz, nada é permanente, tudo está em constante transformação e em inevitável obsolescência como os aparelhos tecnológicos que mal entram no mercado e são substituídos por outros mais modernos a serem consumidos. A pósmodernidade também se identifica com a liquidez que está nas relações entre os homens, nas relações com os objetos e na relação com a vida, trazendo dificuldades para que se promova um sentido subjetivo ao qual nos referimos anteriormente. 
Nossa contemporaneidade também se apresenta como nos mostra Lipovetsky (2005) como uma era da sedução, ou seja, as instâncias de poder e controle representados pelo estado, pela mídia, pelas Igrejas e pelo mercado, como perderam grande parte de sua capacidade de influenciar, principalmente o estado e a igreja, não mais se utilizam da ameaça e da imposição para conseguir que seus desígnios sejam respeitados como ocorria na Idade Média. Hoje é através da sedução que isto é feito, é se utilizando de elementos visuais que seduzem com belas imagens, sons agradáveis, palavras afáveis, discursos melódicos. Esta sedução ocorre por meio de atmosferas agradáveis que são montadas de acordo com as preferências pessoais para que o indivíduo seja controlado sem notar, seduzido, impelido a consumir, conduzido a se cuidar, a se tratar, a se vestir, a se comportar. Enfim, viver como ocorre no mundo das celebridades, no mundo do bemestar, da felicidade e do prazer.

As velhas instituições em crise buscam se adequar aos tempos modernos, buscam se aliar a nova e vitalizada estratégia do capitalismo, para tentar manter a influência que ainda tem, e continuarem como alicerces da sociedade ocidental reorganizando os discursos e os modos de abordagem frente ao sujeito, se apresentando não mais como fonte de dominação, mas sim, como prestadoras de serviço obedecendo à lógica do capitalismo pós-moderno em que tudo é ofertado e está a mão, bastando que se tenha condições sócio-econômicas de adquirir e aproveitar. Desde um reino no céu mediante generosas contribuições a igreja, até serviços públicos de qualidade, contanto que se more em bairros nobres e se tenha amigos influentes (Barth, 2007).

Neste contexto, em geral as pessoas se expressam assim: "para que pensar se tudo vem pronto, enlatado e preparado, pronto para consumir?" A felicidade vem como item de fábrica basta trabalhar duro para ter dinheiro para comprá-la, dispensando um cuidado de si mais acurado, no sentido da busca por construir uma estética da existência como compreendido na Grécia antiga. Ou seja, um cuidado não só corporal como também espiritual, reflexivo e intelectual na busca da melhor constituição da Pólis ou, em termos atuais, em um melhoramento de nossa sociedade brasileira. Enfim, Lipovetsky (1989) nos mostra que o efêmero também é uma marca de nossa atual sociedade já que a dinamicidade e a impermanência são nossas marcas constitutivas na atualidade. Há relatividade desde o uso de objetos, até a consideração dos valores que regem nosso conviver cotidiano, o que nos torna volúveis e de certa forma difíceis de sermos compreendidos por nós mesmos, nos levando a desavenças e conflitos, e a um sentimento de solidão e de falta de lugar.

Nesta conjuntura é que é possível pensar no papel da Psicologia que necessita compreender todo esse movimento sócio-cultural para poder chegar a essa subjetividade e seus processos de subjetivação. E essa compreensão significa para Heidegger (1953) um estar aberto e posicionado para se entender todo esse contexto a fim de auxiliá-la a se demarcar como ser integrante desse novo contexto cultural.

\section{O trabalho da psicologia}

Levando em consideração o que foi discutido acerca da subjetividade, seus processos de subjetivação e a pós-modernidade, abordaremos agora como consideramos que a Psicologia pode se posicionar e trabalhar com essa subjetividade, e de que forma a clínica psicológica deve se adequar a essa nova dinâmica sócio-cultural, se quiser manter seu estatuto de instrumento de compreensão de si por parte dos sujeitos que a procuram. Diante do que foi exposto até agora, podemos perceber que a Psicologia se encontra diante de um grande desafio, que é trabalhar com esse elemento fugaz e intangível que é a subjetividade, vivendo em um contexto sóciocultural que se apresenta também como plural, líquido e dinâmico.

A perda das referências tradicionais que indicamos acima se processa de uma forma muito violenta nos dias de hoje, as rupturas são abruptas levando muitas vezes o sujeito a perder-se em um conglomerado de sentidos e significados que o levam à angústia e à confusão. O que antes era pecado, hoje não é mais, pelo contrário é dispositivo de status e de admiração; o que era tabu hoje é dito e muitas vezes exposto as claras, sem constrangimentos, o que às vezes assusta as mentes mais tradicionais e pouco propensas à mudança.

$\mathrm{Na}$ atualidade lidamos com a presença da tecnologia cada vez mais infiltrada e integrada a vida das pessoas, sendo as redes sociais como assinala Rendeiro (2011) um lugar de exposição pública e de manifestação subjetiva, onde somente ao se expor a intimidade publicamente se é considerado como um ser existente no meio social.

Categorias psicanalíticas que antes eram usadas para se compreender o psiquismo dos indivíduos, hoje são exploradas e estimuladas pela mídia como o voyerismo e o sadismo, seja com seus Big Brothers, ou com novelas ou filmes que aguçam o sentimento de vingança do telespectador. As categorias morais são relativas de acordo com a concepção do subgrupo em que o sujeito está inserido e o ser feliz está fortemente vinculado ao ter e ao usar o que as empresas nos oferecem para consumir.

Esse conjunto de novos paradigmas contrasta com velhos valores e costumes que ainda são valorizados como a concepção do que é família, do que é religião, do que é estado e tantos outros que ainda vigoram na pós-modernidade, gerando muitas vezes contradições irreconciliáveis, deixando pais, professores, líderes sociais ou até mesmo autoridades 
em graves dilemas do que ensinar, do que falar e de que forma proceder. Atravessando tudo isso, estão os mandamentos contemporâneos de produtividade, hiper-aproveitamento do tempo, consumo rápido e conectividade em tempo integral sob o risco de se ficar de fora das tendências e dos acontecimentos da moda e do dia a dia caso não se esteja "antenado".

É nessa teia de circunstâncias que a Psicologia e seu profissional, o Psicólogo, tem que identificar quais sentidos e significados seus clientes estão atribuindo a esse novo momento, se ele está se sentindo dentro ou fora de lugar nesse novo contexto, como ele configura suas relações, como ele compreende essa nova dinâmica de vida e em que lugar ele se encontra nesse novo paradigma. Ele se encontra envolto na liquidez do momento, ou se mantém arraigado com os velhos valores de outrora, ou mais ainda, se está confuso entre os dois. O Psicólogo necessita então, estar atento a nova forma de funcionamento de nossa atual sociedade brasileira, estar aberto a pluralidade das manifestações culturais e sociais que de norte a sul surgem, para que ele possa transformar esse elemento que a priori seria complicador, que é a inconstância das verdades atuais, em benefício de seu cliente, oferecendo-lhe novas configurações significativas visando ao seu crescimento e ao seu desenvolvimento.

Cremos que para isso seja fundamental ao profissional Psicólogo não só a atenção ao que é atual, mas buscar um conhecimento mais amplo, assim como argumenta Crochík (2010) no sentido de possuir conhecimentos mínimos em outras disciplinas de humanidades, como Antropologia, Sociologia, Artes, História entre outras. Estes conhecimentos são necessários para que ele tenha um leque de compreensão mais profundo, não só do que se refere ao sujeito, mas dos diversos fatores que contribuíram para que este sujeito se configure desta forma, além de suas vivências e experiências pessoais.

A compreensão das psicopatologias e das estruturas cerebrais que as regem, é de fundamental importância. Mas uma compreensão mais global, um olhar também para o social, o cultural, o histórico e o econômico, pode auxiliar a identificar fatores que estão diretamente influindo no desenvolvimento de conflitos psíquicos e, naturalmente, de doenças. Portanto, o trabalho do psicólogo em seu âmbito terapêutico deve então também estar atento a estas questões. Pensando assim, afirmam Barros e Holanda (2007): “... a terapêutica do psicológico precisa cuidar da experiência do sujeito que comporta o fenômeno particular; fenômeno este que, embora esteja localizado no indivíduo, reflete e é ainda constituído por elementos do meio" (p. 87). Com isso, as chamadas doenças da contemporaneidade como a hiperatividade, a depressão, os transtornos alimentares, as fobias, pensadas desta maneira, podem ser consideradas como resultado também de influências de nosso atual modo de vida, que, de tão frenético e acelerado, nos gera dificuldade de adaptação, nos obrigando a criarmos formas de existência próprias e às vezes, disruptivas.

$\mathrm{Na}$ era da informação em que nos encontramos, onde esta ganha um valor cada vez mais importante, já que pertencemos a uma época de competitividade, e a informação precisa, pode ser um diferencial no êxito pessoal, um não pertencimento do sujeito nessa lógica frenética em que ele deve estar sempre atento e pronto para agir, pode acarretar-lhe ficar fora da cultura, ser renegado a margem, levando-o a um sentimento de des-pertencimento. Pode leválo a se sentir um estrangeiro em sua própria cultura. Esta intranqüilidade e inquietação que o aflige é característica dos tempos pós-modernos e perturba profundamente os indivíduos, para Evangelista:

Ao mesmo tempo em que tenta e vai conseguindo sobreviver, o homem está envolto por um estado permanente deinsatisfação, ansiedade, intranqüilidade, apatia e uma enorme sensação de vazio interior na vivência do seu cotidiano (Evangelista, 2008, p.21).

O que pode lançá-lo em uma busca compensatória através do uso de drogas, bebidas alcoólicas, abuso de medicamentos psiquiátricos e qualquer tipo de atividade criminosa que lhe possibilite a busca de um resgate de si-mesmo, até mesmo em casos mais extremos, buscar um refúgio nas psicopatologias. $\mathrm{O}$ psicólogo deve então acolher os sentimentos desse sujeito que o procura, ajudando-o a destrinchar toda a cadeia de significados que permeiam a vida contemporânea na tentativa de encontrar um sentido para a vida desse sujeito.

Nessa busca, o objetivo acima de tudo é o resgate de si mesmo, é resgatar nele a condição primordial do que é ser humano, ou seja, a sua capacidade de pensar e refletir sobre sua vida, sua história, sua cultura, seu contexto e sua condição. Para isso, cabe ao psicólogo fornecer um espaço de acolhida e reflexão, para que a subjetividade se expresse e se defronte com novas formas de olhar e pensar os diversos fenômenos que a circundam, para que assim, este sujeito perceba a si mesmo e a seu mundo com liberdade e condição de escolher seu modo de ser, a partir do modo como o mundo se configura e se apresenta.

É dessa forma que se estabelecerá de fato um trabalho terapêutico, com o sujeito acolhido tendo condições e sustentação para desenvolver suas potencialidades com êxito e propriedade, e cabe ao psicólogo oferecer esta condição em seu domínio clínico. Nisso, Rogers aborda assim a questão do posicionamento necessário por parte do terapeuta para que o cliente entre nesse caminho:

Sabemos que, se o terapeuta adotar interiormente em relação ao seu cliente uma atitude de profundo respeito, de aceitação total do cliente tal como ele é e de confiança nas suas potencialidades para resolver os seus próprios problemas; se essas atitudes estiverem impregnadas de suficiente calor para se transformarem 
numa simpatia ou numa afeição profunda pela pessoa; se se atingir um nível de comunicação onde o cliente pode começar a perceber que o terapeuta compreende os sentimentos que está experienciando e que os aceita a um profundo nível de compreensão, nesse momento podemos estar certos de que se iniciou o processo terapêutico ( Rogers, 1977, p.76).

Agindo assim, o psicólogo oferecerá a este sujeito a condição de se apropriar de sua história e sua vida, dando a ele a possibilidade de se tornar um elemento transformador tanto de si mesmo, como de sua sociedade, despertando-lhe a consciência para os elementos que configuram sua vida e fornecendo-lhe a capacidade de adquirir autoconhecimento.

Enfim, o psicólogo e a Psicologia devem se reformular para poder abranger e compreender melhor essa nova realidade cultural e essas novas subjetividades que se configuram. Uma nova proposta para a Psicologia seria a de buscar junto a seus clientes o resgate da chamada consciência crítica, para que aqueles que usufruem dela possam ter a oportunidade não só de atingirem um bem estar psicológico, como também terem a chance de se apoderarem de sua condição de cidadão, com visão política e consciência reflexiva acerca dos malogros que influem em seu modo de vida.

Uma Psicologia como essa só é possível, se o profissional que dela se utiliza, no caso o psicólogo, tiver esse tipo de posicionamento. Tiver o interesse em não se fechar dentro dos padrões dominantes de atuação profissional e adaptar seus clientes a sua penosa realidade, mas, em ajudá-lo a construir sua autonomia, a pensar sobre as contradições da sociedade em que vivemos e unir a promoção de sua saúde mental a um trabalho que podemos considerar até mesmo pedagógico. No sentido de oferecer ao sujeito, a possibilidade de viver sua jornada de vida de forma autêntica e emancipatória, potencializando-o a ser um elemento transformador não só de si, mas também de toda a sua realidade. E tal postura do psicólogo é conquistada quando esse pratica uma clínica da intersubjetividade de acordo com Ayouch (2012), em que ele busca em conjunto com seu paciente permitir o surgimento dessa autonomia, sendo este surgimento uma construção em parceria e em co-participação.

\section{Considerações finais}

Ao final dessas reflexões é possível perceber que abordar a questão da subjetividade é algo complexo devido às várias interpretações que esta pode ter, aliada às várias visões de mundo a que estas se ancoram. Juntar uma análise da subjetividade ligando-a ao modo de vida contemporâneo se torna ainda mais difícil, e o que tentamos neste texto não foi abordar a questão da subjetividade até o seu esgotamento, mas sim, fornecer uma visão possível de como se constitui a subjetividade e seus processos de subjetivação e suas possíveis implicações para a atuação psicoterápica. A ideia foi de se fazer um esforço para compreender a fonte dos dilemas e transtornos que o sujeito contemporâneo enfrenta na constituição de sua subjetividade, e dar indicações de como o profissional psicólogo, através de seu instrumento, a psicologia clínica, pode servir de auxílio e guia em um processo de apropriação dos sujeitos de suas realidades e dificuldades. Acreditamos que o psicólogo interessado e disposto a ajudar realmente seu paciente a entender os processos que o envolvem atualmente, deve antes de tudo compreender estes processos, e isto implica estudo, atenção, e principalmente consciência crítica, para poder discernir acerca dos diversos dispositivos e mecanismos que influem em nossa sociedade atual.

Portanto, trabalhar com o conceito de subjetividade é trabalhar com o indescritível e com o complexo; trabalhar nesse sentido é estar preparado para o aparecimento do novo, do polissêmico, e estar pronto para desfazer e refazer tudo aquilo que foi pensado e discutido anteriormente; é estar aberto a entender que a subjetividade na teoria, assim como na prática, é algo misterioso e mutável, e que os caminhos para sua compreensão passam pela busca do conhecimento incessante e obstinado.

\section{Referências}

Ales Bello, A. (2004). Fenomenologia e ciências humanas: psicologia, história e religião. Bauru, SP: EDUSC, 2004.

Ayouch, T. (2012). Genealogia da intersubjetividade e figurabilidade do afeto: Winnicott e Merleau-Ponty. Psicologia USP v. 23(2), p. 253-274, abr/jun.

Barros, F., Holanda, A. (2007). O Aconselhamento Psicológico e as Possibilidades de uma (Nova) Clínica Psicológica. Revista da Abordagem Gestáltica, v. 13 (1), p.75-95, Jan/Jun.

Barth, W. L. (2007). O homem pós-moderno, religião e ética [Versão eletrônica]. Teocomunicação v. 37(155), Porto Alegre p.89-108, mar.

Bauman, Z. (2001). Modernidade Líquida. Rio de Janeiro: J.Zahar.

Bittencourt, R. N. (2008). A Crise da Cultura Brasileira e o papel atual da Filosofia. Revista Filosofia Capital, v. 3 (6), Rio de Janeiro p. 56-72.

Crochik, J. L. (2010). A forma sem conteúdo e o sujeito sem subjetividade. Psicologia USP, v. 21 (1), São Paulo p. 31-46, Jan/ Mar. Graal.

Deleuze, G. (1988). Diferença e repetição. Rio de Janeiro:

Evangelista, J. E. (2008). Elementos para uma crítica da cultura pós-moderna. Revista Pedagógica Unochapecó v.10 (20), p. 9-32, Jan/Jun.

Ferreira, M. G. (2000). Gênese da concepção de subjetividade. In: Ferreira, M. G. Concepções de Subjetividade em Psicologia (pp.25-61). Campinas: Pontes.

Gonçalves, R. R. (2011). Subjetividade e linguagem na obra de Merleau-Ponty. Psicologia USP v.22 (3), p. 621-634, jul/set.

Guattari, F. (1992). Heterogênese. In: Caosmose (pp. 11-35): Um novo paradigma estético. São Paulo: Editora 34.

Heidegger, M. (1953). El estar-en como tal. In: Ser y Tiempo ( $7^{\mathrm{a}}$ Ed. em espanhol, pp.135-181). Edición Electrónica de Escuela de Filosofia Universidad ARCIS. Acessado de www.philosophia.cl Heidegger, M. (2008). Introdução à Filosofia. São Paulo: Martins Fontes.

Lemos, F. C. S. (2007). História, Cultura e Subjetividade: 
Problematizações [Versão eletrônica]. Revista do Departamento de Psicologia-UFF v. 19 (1), p.61-68, jan/jun.

Lipovetsky, G. (1989). O império do Efêmero: A moda e seus destinos nas sociedades modernas. São Paulo: Companhia das Letras.

Lipovestsky, G. (2000). Sedução, publicidade e pósmodernidade [Versão eletrônica]. Revista FAMECOS, Porto Alegre, n. 12, p. 7-13, jun.

Lipovetsky, G. (2005). A Era do Vazio: ensaios sobre o individualismo Contemporâneo. Barueri: Manole.

Maciel Junior, A., Melo, D. A. S. (2006). A fundação do subjetivo: O hábito para além da psicologia. Revista do Departamento de Psicologia- UFF v. 18 (2), p. 69-82, Jul/Dez.

May, R. (1994). O Homem a procura de si mesmo. PetrópolisRJ: Vozes.

Piéron, H. (1978). Dicionário de Psicologia. Porto Alegre: Editora Globo.

Prado Filho, K. , Martins, S. (2007). A Subjetividade como objeto da(s) Psicologia(s) [Versão eletrônica]. Psicologia e Sociedade v. 19 (3), p.14-19.

Rendeiro, M. E. (2011). Orkut e Facebook: as teias da memória em meio às redes sociais [Versão eletrônica]. Ciências Sociais Unisinos v.47 (3), p. 256-262, set/dez.

Rey, F. L. G. (2003). A subjetividade e as teorias de inspiração social na Psicologia. In: Rey, F. L. G. Sujeito e Subjetividade (pp.121-187): Uma aproximação histórica-cultural. São Paulo: Thomson.

Rogers, C. R. (1977). Tornar-se Pessoa. São Paulo: Martins Fontes.

Sartre, J.P (2009). O Ser e o Nada: Ensaio de Ontologia Fenomenológica (18 $8^{\mathrm{a}}$ Ed.). Petrópolis, RJ: Vozes.

Tedesco, S. (2003). A natureza coletiva do elo linguagemsubjetividade. Psicologia: Teoria e Pesquisa v. 19 (1), p. 85-89, Jan/ Abr.

Sobre os autores:

André Luiz de Oliveira - Psicólogo graduado no curso de Psicologia, da Pontifícia Universidade Católica de Minas Gerais, campus Poços de Caldas. E-mail: Andrepsico07@gmail.com. Tel: (35) 88313874. Este autor disponível para contato.

Ellika Trindade - Dra. e Mestre em Psicologia pela FFCLRP-USP E-mail: ellika@pucpcaldas.br 